\title{
Mitochondrial DNA content in peripheral blood monocytes: relationship with age of diabetes onset and diabetic complications
}

\author{
J. Wong • S. V. McLennan • L. Molyneaux • D. Min • \\ S. M. Twigg • D. K. Yue
}

Received: 31 March 2009 /Accepted: 27 April 2009 /Published online: 21 July 2009

(C) Springer-Verlag 2009

\begin{abstract}
Aims/hypothesis We examined whether age of type 2 diabetes onset is related to mitochondrial DNA content in peripheral blood monocytes (PBMCs).

Methods PBMCs were isolated from 65 patients with type 2 diabetes. To minimise age as a confounder, only patients aged $\geq 50$ years were studied. Sample mitochondrial DNA (mtDNA) content was determined by amplification of the mitochondrial gene CYT-B (also known as MT-CYB) and adjusted for single-copy nuclear control genes (36B4 [also known as RPLPO] and GAPDH).

Results Age of diabetes onset ranged from 25 to 69 years. There was a significant positive relationship between age of diabetes onset in quartiles and mtDNA content for the whole group ( $p=0.02$ for trend). When stratified by the presence of diabetes complications, a strong positive relationship was observed between age of diagnosis and mtDNA content for participants without diabetic complications $(r=0.7 ; p=0.0002)$, but not for those with complications $(r=-0.04 ; p=0.8)$. Multivariate analysis confirmed age of onset and complication status as independent determinants. There was co-linearity between
\end{abstract}

J. Wong $(\bowtie) \cdot$ L. Molyneaux $\cdot$ S. M. Twigg $\cdot$ D. K. Yue

Diabetes Centre, Royal Prince Alfred Hospital,

Level 6, West Wing, Missenden Road, Camperdown,

Sydney, NSW 2050, Australia

e-mail: jencia.wong@email.cs.nsw.gov.au

J. Wong $\cdot$ S. V. McLennan $\cdot$ L. Molyneaux $\cdot$ S. M. Twigg $\cdot$

D. K. Yue

Discipline of Medicine, University of Sydney,

Sydney, NSW, Australia

J. Wong $\cdot$ S. V. McLennan · D. Min · S. M. Twigg $\cdot$ D. K. Yue Department of Endocrinology, Royal Prince Alfred Hospital, Sydney, NSW, Australia age of onset and disease duration, with similar relationships also seen between duration and mtDNA content. Conclusions/interpretation An earlier age of type 2 diabetes onset is associated with a lower PBMC mtDNA content, but only in patients without diabetes complications. This may reflect a differing biology of PBMC mtDNA in those with early-onset diabetes and those who are prone to complications. PBMC mtDNA depletion may accelerate diabetes onset; however the independent effect of diabetes duration remains to be evaluated.

Keywords Age of onset - Diabetic complications · DNA . Macrophage $\cdot$ Mitochondria $\cdot$ Monocyte $\cdot$ Type 2 diabetes

$\begin{array}{ll}\text { Abbreviations } \\ \mathrm{C}_{\mathrm{t}} & \text { Cycle threshold } \\ \Delta \Delta \mathrm{C}_{\mathrm{t}} & \text { Relative cycle threshold } \\ \text { eNOS } & \text { Endothelial nitric oxide synthase } \\ \text { mtDNA } & \text { Mitochondrial DNA } \\ \text { nDNA } & \text { Nuclear DNA } \\ \text { PBMC } & \text { Peripheral blood monocyte } \\ \text { ROS } & \text { Reactive oxygen species } \\ \text { TZD } & \text { Thiazolidinedione }\end{array}$

\section{Introduction}

An insight into the specific molecular factors that determine the age at which type 2 diabetes develops is now most relevant, as early-onset type 2 diabetes is becoming increasingly prevalent. This form of diabetes appears to be phenotypically more aggressive, with poorer metabolic control at presentation and an inherent increased risk of retinopathy compared with later onset disease [1-3]. 
It has been recognised for some time that patients with specific mutations in the mitochondrial genome often present with diabetes at a young age [4]. Furthermore there is now substantial evidence suggesting that abnormalities in mitochondrial oxidative capacity and biogenesis also contribute to the development of the more common variety of type 2 diabetes. Thus mitochondrial dysfunction may lead to impaired insulin action and glucose-stimulated insulin secretion [5]; such mitochondrial defects, importantly, may be found in offspring of type 2 diabetic patients, confirming the heritability of these traits [6]. In addition to qualitative defects in mitochondrial function, quantitative alterations in mitochondrial DNA (mtDNA) have been implicated in the genesis of diabetes. Depletion of mtDNA in pancreatic islets was seen in rodent models of type 2 diabetes [7] and reduced mtDNA content has also been reported in skeletal muscle from patients with type 2 diabetes [8]. Indeed mtDNA content and mitochondrial functional capacity have been found to be closely correlated [9]. In this study we therefore examined the role of mtDNA content as a factor affecting the timing of type 2 diabetes development.

Although previous mitochondrial studies in type 2 diabetes have focused mainly on skeletal muscle and both adipose and pancreatic tissue, mtDNA content in peripheral blood cells has also been studied as a surrogate [10]. Depletion of peripheral blood leucocyte mtDNA has been shown to correlate with insulin resistance and to precede the development of type 2 diabetes [11]. In this regard, the monocyte-macrophage lineage could be of particular importance. These cells are thought to play a pivotal role in the low-grade inflammation that characterises type 2 diabetes. Indeed, preclinical studies have shown that genetic disruption of macrophage biology alone can greatly modulate insulin sensitivity, potentially via mitochondrial pathways [12]. Thus in this study we specifically examined the hypothesis that a reduced peripheral blood monocyte (PBMC) mtDNA content is associated with an earlier age of type 2 diabetes onset.

\section{Methods \\ Patients}

We studied 65 type 2 diabetic patients attending the Royal Prince Alfred Hospital Diabetes Centre, Sydney, for an annual complications assessment. As previous studies have indicated an age-related decline in mtDNA content, we sought to reduce the confounding impact of age by studying only patients aged $\geq 50$ years [13]. Patients were excluded if taking HIV medications or had a known haematological malignancy. The study protocol was approved by the Sydney South West Area Health Service Ethics Committee and informed consent was obtained from all subjects.

All patients underwent a complications assessment and data were collected following a standardised protocol as described previously [14]. Retinopathy status was assessed by direct fundoscopy through dilated pupils or by report from the treating ophthalmologist and severity scored using a modified Early Treatment Diabetic Retinopathy Study severity scale [15]. Microalbuminuria status was assessed by urine albumin:creatinine ratio. The presence of neuropathy was determined clinically by the combination of symptoms and elevated age-specific biothesiometer readings. A detailed history, including the presence of ischaemic heart disease, coronary artery bypass graft, cerebrovascular events, peripheral vascular disease and age of diagnosis of type 2 diabetes, was recorded. All patients were examined for the presence of peripheral vascular disease and vascular bruits. The presence of diabetes complications was defined as the presence of retinopathy, albuminuria or neuropathy, or evidence of macrovascular disease. Patients were classified as having the metabolic syndrome by WHO criteria [16]. Samples from 27 non-diabetic participants (average age $42.2 \pm 12.4$ years) were also analysed as a comparator.

Isolation of peripheral blood monocytes and preparation of DNA

PBMCs were isolated from whole blood using OptiPrep (Sigma, St Louis, MO, USA). The yield of cells ranged from $4 \times 10^{4}$ to $726 \times 10^{4} \mathrm{PBMCs} / \mathrm{ml}$. After separation, cells were stored at $-20^{\circ} \mathrm{C}$. All samples were treated in the same manner and batched for DNA extraction. Total DNA was extracted from PBMCs using a kit (QIAamp DNA Blood Midi Kit; Qiagen, Hilden, Germany) designed to extract both nuclear and mtDNA, and the DNA concentration was determined using a Spectrophotometer (NanoDrop; Thermo Scientific, Willmington, DE, USA).

Flow cytometric analysis

The recovery and purity of PBMC preparations from representative whole-blood specimens were analysed by flow cytometry (FACSAria, BD BioSciences, San Jose, CA, USA) using the monocyte-specific marker CD14. The cell populations were also gated on high forwardscatter for further assurance of monocyte characteristics. Data were analysed using FlowJo (Ashland, OR, USA) and treatments were compared with an isotype control. The result from a representative sample is shown in Fig. 1. The percentages of $\mathrm{CD} 14^{+}$cells were $1.3 \%, 14.6 \%$ and $74.9 \%$ in isotype control, whole blood and isolated PBMCs respectively. 
a

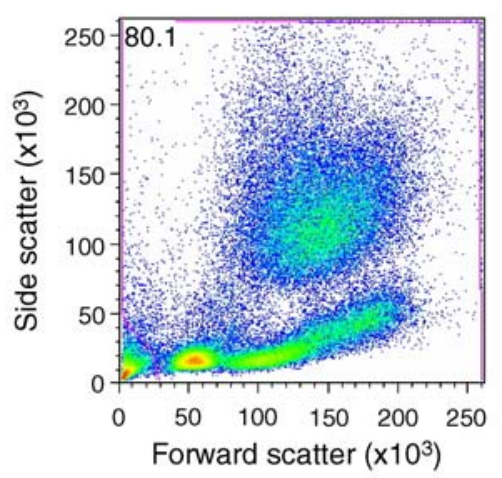

b

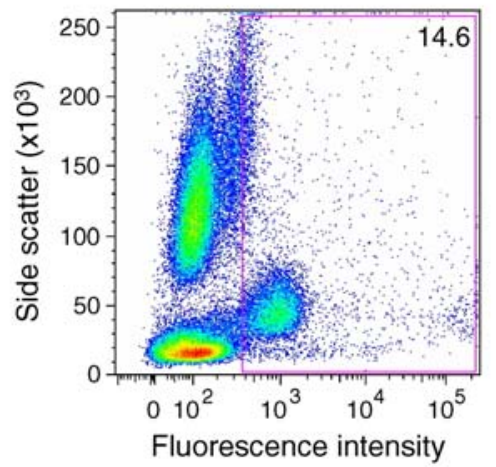

c

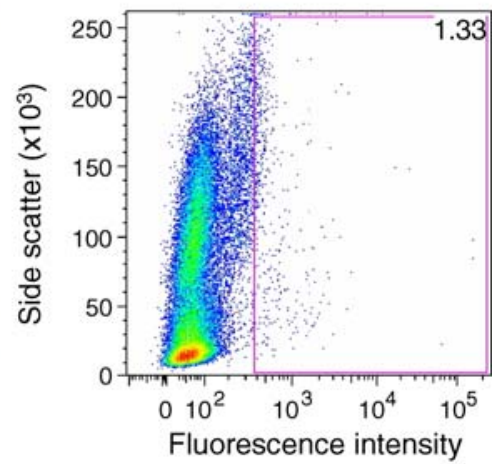

d

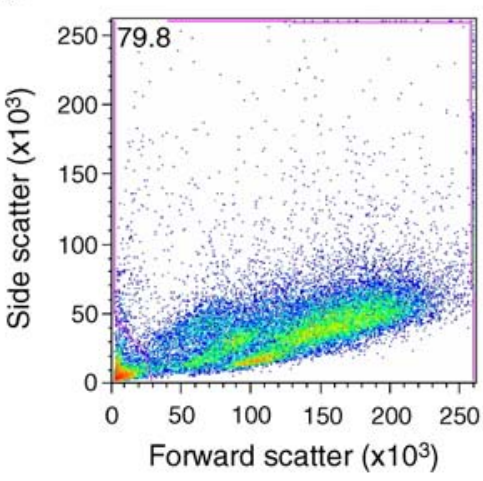

e

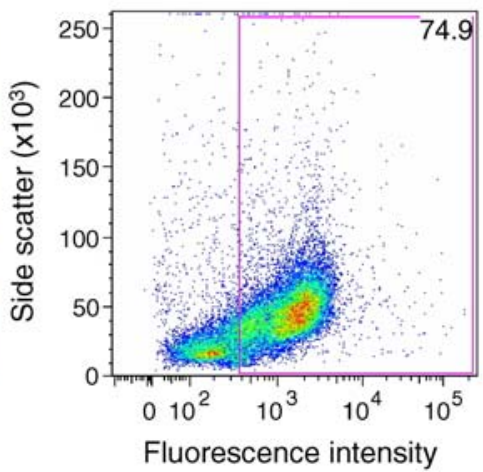

Fig. 1 Results of flow cytometry from a representative sample showing purification of PBMCs by labelling antigen (CD14) for a-c whole blood and $\mathbf{d}$, e isolated PBMCs. (a), (d) show dot plots of forward scatter against side scatter. Data were obtained by gating cells to exclude cell debris, with $\%$ of total cell population shown in top

Quantitative analysis of mtDNA content

Relative amounts of mtDNA and nuclear DNA (nDNA) were determined by real-time RT-PCR. Mitochondrial DNA content in PBMCs was determined by quantification of $C Y T-B$ (also known as $M T-C Y B$ ), a conserved single-copy gene encoded in mtDNA. Two types of analysis were used to quantify mtDNA content: (1) absolute standard curve method; and (2) relative cycle threshold $\left(\Delta \Delta C_{t}\right)$ with comparison to an internal control. Results were corrected for differences in starting DNA concentration and loading efficiency by measurement of the single-copy nuclear genes $36 B 4$ [also known as RPLPO] or GAPDH.

Analysis of mtDNA content using absolute standard curves

Briefly a $131 \mathrm{bp}$ fragment of the $C Y T-B$ PCR product was cloned into a plasmid vector (pGEM T-Easy; Invitrogen, Melbourne, VIC, Australia) [17]. Plasmid standards of known copy number and PCR were used to generate loglinear standard curves for $C Y T-B$ and the nuclear control gene $36 B 4$. The sample $C Y T-B$ and $36 B 4$ copy number was left. For (b), (c), (e), data were obtained by gating FITC cells. Results are expressed as single-colour dot plots and show the percentage of FITC-positive cells (top right) in whole blood to be $14.6 \%$ (b), in the isotypic control 1.3\% (c) and in the isolated PBMCs $74.9 \%$ (e)

then determined as described below. The identity of each fragment was confirmed by sequencing (Supamac, Sydney, NSW, Australia). All samples were run in triplicate.

Mitochondrial target gene: $C Y T-B$ Quantification of $C Y T-B$ was determined by RT-PCR using a kit (Platinum Plus QPCR-UDG; Invitrogen). Primers for $C Y T-B$ were: forward 5'GCCTGCCTGATCCTCCAAAT3'; reverse 5'AAGGTAGCGGATGATTCAGCC3'. The RT-PCR reaction $(15 \mu \mathrm{l})$ contained $0.5 \mu \mathrm{mol} / \mathrm{l}$ of primers and $1 \mathrm{ng}$ of DNA, and the products were amplified as follows: $2 \mathrm{~min}$ at $60^{\circ} \mathrm{C} ; 10 \mathrm{~min}$ at $95^{\circ} \mathrm{C}$; and 40 cycles of $95^{\circ} \mathrm{C} 10 \mathrm{~s}, 62^{\circ} \mathrm{C}$ $15 \mathrm{~s}$ and $72^{\circ} \mathrm{C} 20 \mathrm{~s}$. The (mean) cycle thresholds $\left(\mathrm{C}_{\mathrm{t}}\right)$ were compared with plasmid standards (range: 10.2-10.2 $\times 10^{4}$ copies) and the sample copy number was determined. Dilution curves for plasmid and sample were run to ensure the $\mathrm{Ct}$ values for all unknown samples fell within the linear amplification range.

Nuclear DNA housekeeper gene: $36 B 4$ The $36 B 4$ gene product was amplified as for the $C Y T-B$ gene using forward 5'CAGCAAGTGGGAAGGTGTAATCC3' and 
reverse 5'CCCATTCTATCATCAACGGGTACAA3' primers at concentrations of $150 \mathrm{nmol} / 1$ and $250 \mathrm{nmol} / 1$ respectively. The following PCR conditions were used: $2 \mathrm{~min}$ at $60^{\circ} \mathrm{C}$; $10 \mathrm{~min}$ at $95^{\circ} \mathrm{C}$; and 40 cycles of $95^{\circ} \mathrm{C} 10 \mathrm{~s}, 62^{\circ} \mathrm{C} 20 \mathrm{~s}$ and $72^{\circ} \mathrm{C} 20 \mathrm{~s}$. Sample copy number was determined from analysis of the $36 B 4$ standard curve (range: $10.2-10.2 \times 10^{4}$ copies).

The $C Y T-B$ and $36 B 4$ amplified with similar efficiency in both sample and plasmid (CYT-B: 105 and 98\%, 36B4: 105 and $109 \%$ respectively). For both $C Y T-B$ and $36 B 4$, the between-run variance in $\mathrm{C}_{\mathrm{t}}$ was $\leq 0.5 \mathrm{SD}$. Intraindividual variation examined by drawing blood from a participant on three occasions a few weeks apart was 0.01 to 0.05 for $C Y T-B$ and 0.08 to 0.36 for $36 B 4$. The SD of mtDNA:nDNA was 0.012 . The correlation coefficients of standard curves used were $>0.97$ and the majority were 0.99. Using this absolute standard curve analysis method, results are expressed as the ratio $C Y T-B$ copy number:36B4 copy number (i.e. mtDNA:nDNA).

Analysis of mtDNA content using relative quantification of cycle threshold ( $\Delta \Delta \mathrm{C}_{\mathrm{t}}$ method)

Importantly for the $\Delta \Delta \mathrm{C}_{\mathrm{t}}$ method [18], sample mitochondrial and nuclear targets amplified with similar high efficiencies ( $C Y T-B$ 105\%, $36 B 4105 \%$ and $G A P D H$ $101 \%$ ). RT-PCR was performed as described and the results analysed by comparison of the sample $C_{t}$ values with an internal standard $\left(\Delta \mathrm{C}_{\mathrm{t}}\right)$, included in each run. Data were then corrected for the $\Delta \mathrm{C}_{\mathrm{t}}$ of nuclear housekeeper DNA $36 B 4$ or as an additional control, $G A P D H$, as follows

$2^{\Delta \mathrm{C}_{\mathrm{t}} C Y T-B=\left(\text { standard control }-\mathrm{C}_{\mathrm{t}} \text { sample }\right)}$

$2^{\Delta C_{t}}$ housekeeper $=\left(\right.$ standard control $-C_{t}$ sample $)$

Results are designated $\Delta \Delta \mathrm{C}_{\mathrm{t}}$

Nuclear DNA housekeeper gene: GAPDH The GAPDH gene product (286 bp) was amplified from $0.2 \mathrm{ng}$ of sample DNA using forward 5'CCACCATGGAGAAGGCTGG GGC3' and reverse 5'AGTGATGGCATGGACTGTGGTC3' primers (both $0.5 \mu \mathrm{mol} / 1$ ), and PCR conditions as follows: $2 \mathrm{~min}$ at $60^{\circ} \mathrm{C} ; 10 \mathrm{~min} 95^{\circ} \mathrm{C}$; and 40 cycles of $95^{\circ} \mathrm{C} 10 \mathrm{~s}, 58^{\circ} \mathrm{C}$ for $20 \mathrm{~s}$ and $72^{\circ} \mathrm{C}$ for $20 \mathrm{~s}$.

\section{Statistical analysis}

Data were analysed using the NCSS 2004 statistical software (Kaysville, UT, USA). Continuous data were checked for normality and presented as mean $\pm \mathrm{SD}$ or median and interquartile range. Data not normally distributed were log-transformed. Categorical data were compared by $\chi^{2}$ test. Data were grouped into quartiles according to age of diagnosis of diabetes and compared using ANOVA or $\chi^{2}$ test. Trend tests were performed between the groups for mtDNA content. Pearson's coefficient was used to assess the relationship between mtDNA content and age of onset of type 2 diabetes, duration of diabetes and age. Multiple regression was performed to determine the independent predictors of mtDNA content using the whole group or in groups as defined by complication status. Predictors examined included age of diagnosis of diabetes, duration of diabetes, $\mathrm{HbA}_{1 \mathrm{c}}$, BMI, thiazolidindione (TZD) and metformin use, sex, ethnicity and family history of diabetes, smoking history and micro- or macrovascular complications status. The model was determined using a backward stepwise method, with variables that were significant included in the final model. Interactions were tested between the age of diagnosis (or duration of diabetes) and the presence of micro- or macrovascular complications. Statistical significance was accepted at $p<0.05$. Power calculations were performed to test the required size of the study population and showed that 28 participants for each group (age of onset above and below 40 years) were needed to detect a 0.03 difference in mtDNA:nDNA at a 0.05 significance level with $80 \%$ power.

\section{Results}

Age of type 2 diabetes onset and other factors affecting PBMC mtDNA

Analysis of the age of onset of diabetes as a categorical variable showed a statistically significant trend for a lower PBMC mtDNA content in participants with early-onset type 2 diabetes. This was evident regardless of whether mtDNA content was analysed using the standard curve or the $\Delta \Delta \mathrm{C}_{\mathrm{t}}$ method (Table 1).

When mtDNA content (measured by the standard curve method) was analysed as a continuous variable, a positive relationship between age of diagnosis and mtDNA was particularly striking and statistically significant for participants without diabetic complications $(r=0.7 ; p=0.0002)$ (Fig. 2a). By contrast, there was no such relationship in the presence of complications $(r=-0.04 ; p=0.8)$ (Fig. 2b). In agreement with these findings, the relationship between age of onset and mtDNA demonstrated in the absence of complications was the same when mtDNA was measured by $\Delta \Delta \mathrm{C}_{\mathrm{t}}$ analysis, using $36 B 4$ and $G A P D H$ as control genes, i.e. mtDNA by $\Delta \Delta C_{t}$ correlated with age of onset in participants without diabetic complications (36B4 $r=0.8$, 
Table 1 mtDNA content and clinical data by age of onset of diabetes

\begin{tabular}{|c|c|c|c|c|c|c|c|}
\hline \multirow[t]{2}{*}{ Variable } & \multicolumn{4}{|c|}{ Age of onset (years) } & \multirow[t]{2}{*}{$F$} & \multirow[t]{2}{*}{$T_{\text {trend }}$} & \multirow[t]{2}{*}{$\chi^{2}$} \\
\hline & $\leq 40$ & $41-50$ & $51-60$ & $>60$ & & & \\
\hline$n$ & 15 & 14 & 26 & 10 & & & \\
\hline mtDNA/nDNA & $0.36 \pm 0.5$ & $0.34 \pm 0.3$ & $0.37 \pm 0.4$ & $0.40 \pm 0.4$ & $4.1(p=0.01)$ & $2.5(p=0.02)$ & \\
\hline$\Delta \Delta \mathrm{C}_{\mathrm{t}} 36 B 4$ & $14(3.3-50.3)$ & $29.9(15.6-38.0)$ & $32.2(14.1-48.8)$ & $62.6(31.5-153.4)$ & $2.7(p=0.05)$ & $2.8(p=0.006)$ & $7.1(p=0.07)$ \\
\hline Age (years) & $62.3 \pm 7.3$ & $58.2 \pm 5.7$ & $65.9 \pm 6.9$ & $71.5 \pm 3.8$ & $9.9(p<0.0001)$ & & \\
\hline Age of diagnosis (years) & $32.9 \pm 7.1$ & $48.1 \pm 1.9$ & $55.3 \pm 3.2$ & $64.8 \pm 4.2$ & & & \\
\hline Duration (years) & $28(25-36)$ & $10(5-15)$ & $10(4-16)$ & $8(3-9)$ & & & $32.2(p<0.0001)$ \\
\hline Men $(\%)$ & 86 & 73 & 65 & 60 & & & $2.5(p=0.5)$ \\
\hline Family History (\%) & 86 & 60 & 73 & 50 & & & $2.1(p=0.6)$ \\
\hline Mother with diabetes (\%) & 43 & 33 & 39 & 10 & & & $3.3(p=0.3)$ \\
\hline Father with diabetes $(\%)$ & 21 & 13 & 12 & 30 & & & $2.1(p=0.6)$ \\
\hline Weight (kg) & $86.3 \pm 15.4$ & $91.6 \pm 23.0$ & $85.5 \pm 20.9$ & $77.3 \pm 18.0$ & $1.0(p=0.4)$ & & \\
\hline BMI $\left(\mathrm{kg} / \mathrm{m}^{2}\right)$ & $29.7 \pm 5.0$ & $31.0 \pm 6.6$ & $30.0 \pm 5.8$ & $27.6 \pm 4.7$ & $0.7(p=0.5)$ & & \\
\hline $\mathrm{HbA}_{1 \mathrm{c}}(\%)$ & $8.0 \pm 1.4$ & $7.5 \pm 1.3$ & $7.0 \pm 0.8$ & $7.0 \pm 1.1$ & $2.7(p=0.052)$ & $2.4(p=0.02)$ & \\
\hline WHO MetS (\%) & 64.3 & 73.3 & 65.4 & 44.4 & & $(p=0.4)$ & $2.1(p=0.6)$ \\
\hline Waist/hip ratio & $1.0 \pm 0.06$ & $1.0 \pm 0.2$ & $1.0 \pm .2$ & $1.0 \pm 0.07$ & $0.2(p=0.9)$ & & \\
\hline Systolic BP (mmHg) & $132 \pm 14$ & $131 \pm 11$ & $136 \pm 18$ & $131 \pm 14$ & $0.5(p=0.7)$ & & \\
\hline Diastolic BP (mmHg) & $74 \pm 10$ & $75 \pm 10$ & $76 \pm 11$ & $77 \pm 18$ & $0.1(p=0.9)$ & & \\
\hline BP Rx (\%) & 93 & 80 & 81 & 90 & & & \\
\hline Total cholesterol (mmol/1) & $3.5 \pm 1.0$ & $4.6 \pm 1.0$ & $4.3 \pm 1.0$ & $4.2 \pm 0.8$ & $3.1(p=0.03)$ & & \\
\hline HDL (mmol/l) & $1.0(0.8-1.3)$ & $1.1(1.0-1.3)$ & $1.1(1.0-1.5)$ & $1.4(1.2-1.7)$ & & & $6.4(p=0.09)$ \\
\hline Triacylglycerol (mmol/l) & $1.1(0.9-2.5)$ & $1.9(1.3-2.2)$ & $1.7(1.2-2.3)$ & $1.2(1.0-1.5)$ & & & $6.0(p=0.1)$ \\
\hline $\begin{array}{l}\text { Albumin/creatinine ratio } \\
(\mathrm{mg} / \mathrm{mmol})\end{array}$ & $3.1(1.2-14.8)$ & $1.2(0.4-6.7)$ & $1.4(0.6-3.3)$ & $2.2(0.5-10.3)$ & & & $4.3(p=0.4)$ \\
\hline Retinopathy (\%) & 64 & 27 & 8 & 40 & & & \\
\hline IHD (\%) & 50 & 13 & 15 & 40 & & & \\
\hline Neuropathy (\%) & 36 & 20 & 8 & 20 & & & \\
\hline
\end{tabular}

Unless otherwise indicated, values are mean $\pm \mathrm{SD}$ or medians (interquartile range)

IHD, ischaemic heart disease; MetS, metabolic syndrome; Rx, treatment

$p<0.0001 ;$ GAPDH $r=0.4, p=0.02$ ), while it did not correlate with age of onset in those with complications (36B4 $r=0.1, p=0.4$; GAPDH $r=0.03, p=0.9$ ).

There was no difference in mtDNA content for participants without or with complications or in non-diabetic comparator participants (mtDNA:nDNA $0.36 \pm 0.06,0.36 \pm 0.04,0.34 \pm 0.06, p=0.3$, respectively). Additionally no difference was observed between the complications and no-complications groups in terms of medication use that might impact on mtDNA, e.g. TZD or statin medications (TZD $59 \%$ vs $43 \%, p=0.5$; statin $43 \%$ vs $61 \%, p=0.2$ for the no-complications vs complications groups respectively).

In the same manner, there was also a significant inverse relationship between duration of diabetes and mtDNA content for participants without complications $(r=-0.5, p=0.008)$ (Fig. 3), but not for those with complications $(r=0.1 ; p=0.4)$ (Fig. 3). Due to the study design, with selection only of patients aged $\geq 50$ years, there was no significant relationship between age and mtDNA content $(p=0.2)$ for the whole group or by complication status ( $p=0.2$ and $p=0.5$ for nocomplications and complications respectively).

Other clinical characteristics of participants by age of diabetes onset are shown in Table 1. Those with early-onset diabetes had worse glycaemic control as judged by $\mathrm{HbA}_{1 \mathrm{c}}$. There was no difference in ethnicity between the age of onset groups with the majority of patients being of AngloCeltic origin $(p=0.9)$. Metformin use was $100 \%, 100 \%$, $92 \%$ and $70 \%$; TZD use was $14 \%, 7 \%, 8 \%$ and $20 \%$; and insulin use was $79 \%, 20 \%, 23 \%$ and $20 \%$ for increasing age of onset quartiles respectively. There was a trend towards more maternal diabetes in participants with younger age of onset, although this was not statistically significant $(p=0.3)$. No statistically significant difference was noted in the prevalence of the metabolic syndrome between age of onset quartiles $(p=0.6)$. 

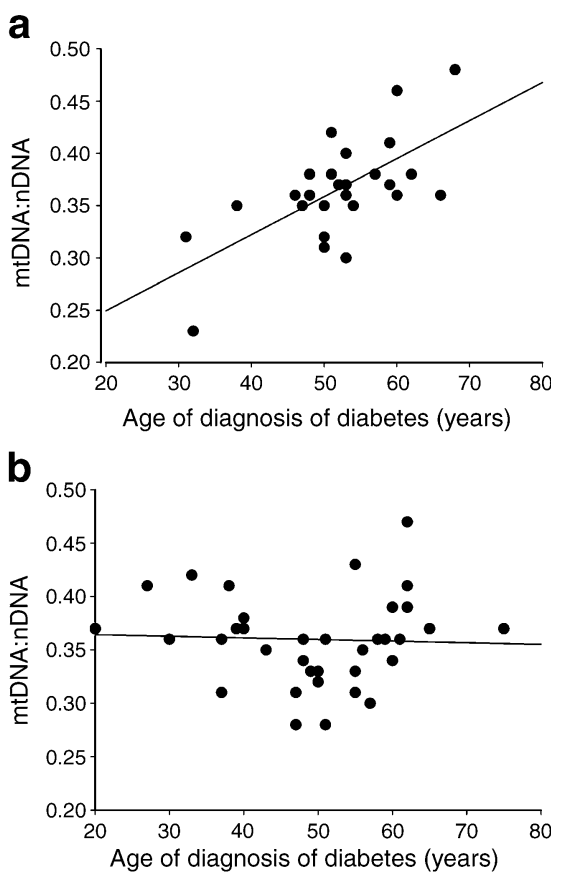

Fig. 2 Relationship between age of diagnosis and mtDNA:nDNA (a) in participants without diabetes complications $(r=0.7, p=0.0002)$ and (b) in those with complications $(r=-0.04, p=0.8)$

Independent determinants of mtDNA by multivariate analysis

Results from multivariate regression analysis are shown in Table 2. As participants with early-onset diabetes also had a long duration of diabetes, there was significant co-linearity between these two factors, which were therefore analysed separately in the regression models. Age of onset was a significant independent predictor of mtDNA content $(p=0.0001)$, with earlier onset diabetes associated with lower mtDNA; there was also a significant interaction between both age of onset and complications status, on mtDNA ( $t=-3.2 ; p=0.002$ for mtDNA:nDNA). As with univariate analysis, age of onset was a significant predictor of mtDNA

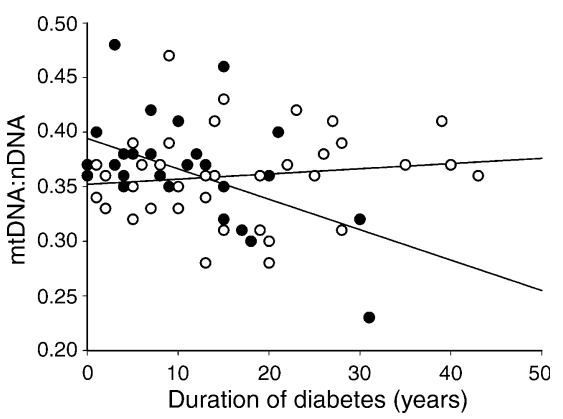

Fig. 3 Relationship between duration of diabetes and mtDNA:nDNA for the no-complications group (black circles) $(r=-0.5, p=0.008)$ and for the complications group (white circles) $(r=0.1, p=0.4)$ content, if the patient group was confined to those without complications $(p \leq 0.0003)$, but this was not the case in patients with complications. Duration of diabetes was also a significant predictor of mtDNA content $(p=0.007)$, but less so than for age of diagnosis. Similarly, there was an interaction between duration of diabetes and complications status on mtDNA content; however, the magnitude of effect was less than that for age of onset. It is notable that in the respective models, age of onset accounted for over $30 \%$ of the variance in mtDNA content, whereas duration of diabetes accounted for less than $20 \%$.

In addition to age of onset or disease duration, other significant factors with a positive association with mtDNA content were BMI, Asian ethnicity and smoking history (Table 2). There was a notable inverse association between $\mathrm{HbA}_{1 \mathrm{c}}$ and mtDNA content.

\section{Discussion}

Several studies to date have looked at the molecular determinants of age of type 2 diabetes onset [19-27]; however none have explored mtDNA content as a candidate factor. Our study suggests that an earlier age of type 2 diabetes onset is associated with a lower PBMC mtDNA content and that this relationship occurs primarily in patients without diabetes complications. The presence of diabetes complications greatly modifies this effect, suggesting that PBMC mtDNA behaves differently in those who are prone to complications.

Why might a lower PBMC mtDNA in early-onset disease exist, and if we postulate a causal effect, what might be the mechanisms? The mechanisms that control mtDNA content are yet to be fully elucidated. There is evidence that PBMC mtDNA content has a large genetic determinant [28] and also evidence suggesting a role for mitochondria and mtDNA content in both insulin secretion and insulin action. Thus rodent models of diabetes show reduced mtDNA content in islet cells [7] and those with genetic disruption of mitochondrial transcription factor $\mathrm{A}$ in pancreatic beta cells exhibit depleted mtDNA and early diabetes [29]. Decreased mtDNA content has been found in skeletal muscle of patients with type 2 diabetes [8] and elegant studies by Petersen et al. [6] have found that impaired mitochondrial function in skeletal muscle of offspring of patients with type 2 diabetes is coupled with an increase in intramyocellular lipid and insulin resistance. Thus PBMC mtDNA depletion may indicate a greater depletion of islet or muscle mtDNA content and a greater bioenergetic defect affecting islet function and insulin action, thereby leading to earlier onset of overt diabetes.

Additionally, there is increasing evidence that the monocyte-macrophage lineage plays an independent and 
Table 2 Results of multiple regression analysis for predictors of mtDNA content

\begin{tabular}{|c|c|c|c|c|}
\hline \multirow[t]{2}{*}{ Model } & \multicolumn{2}{|c|}{ mtDNA:nDNA } & \multicolumn{2}{|c|}{$\Delta \Delta \mathrm{C}_{\mathrm{t}}(\log )$} \\
\hline & $R^{2}(\%)$ & $t$ & $R^{2}(\%)$ & $t$ \\
\hline \multicolumn{5}{|c|}{ Model: With age of diagnosis (years) as independent variable } \\
\hline Age of diagnosis: whole group & 34.8 & $4.4 p=0.0001$ & 40.3 & $3.9 p=0.0003$ \\
\hline Age of diagnosis: without complications $\mathrm{s}^{\mathrm{a}}$ & & $4.3 p=0.0003$ & & $7.5 p<0.0001$ \\
\hline Age of diagnosis: with complications ${ }^{\mathrm{a}}$ & & NS & & NS \\
\hline $\mathrm{HbA}_{1 \mathrm{c}}$ & & $-2.2 p=0.03$ & & $-2.1 p=0.04$ \\
\hline Asian & & $2.8 p=0.007$ & & $3 p=0.004$ \\
\hline History of smoking & & NS & & $2.8 p=0.007$ \\
\hline BMI & & NS & & $2.1 p=0.04$ \\
\hline Complications & & $4.4 p<0.0001$ & & $2.9 p=0.005$ \\
\hline Age of diagnosis/complications interactions & & $-3.2 p=0.002$ & & $-3.2 p=0.003$ \\
\hline \multicolumn{5}{|c|}{ Model: With duration of diabetes (years) as independent variable } \\
\hline Duration & 19.2 & $-2.8 p=0.007$ & 18.9 & $-3.3 p=0.002$ \\
\hline $\mathrm{HbA}_{1 \mathrm{c}}$ & & $-2.2 p=0.04$ & & NS \\
\hline Complications & & $-2.1 p=0.04$ & & $-2.0 p=0.04$ \\
\hline Duration/complications interactions & & $3.1 p=0.003$ & & $2.1 p=0.04$ \\
\hline
\end{tabular}

Predictors in model: age of diagnosis or diabetes duration, family history, ethnicity, BMI, $\mathrm{HbA}_{1 \mathrm{c}}$, smoking, TZD or metformin use, and presence of microvascular and/or macrovascular complications

${ }^{a}$ Results for age of diagnosis as a predictor when analysed separately by complications status

pathogenic role in the development of type 2 diabetes. Monocyte-macrophages are recruited to obese adipose tissue and produce pro-inflammatory mediators that disrupt insulin receptor signalling pathways and contribute to insulin resistance [30]. A myeloid-specific knockout of inhibitor of nuclear factor kappa-B kinase subunit beta in mice results in disruption of inflammatory pathways in macrophages specifically and protects against diet-induced insulin resistance [12]. Recently, inactivation of a single murine macrophage gene, Pparg, resulted in glucose intolerance and insulin resistance, which was only partially responsive to TZD intervention [31]. Furthermore, increased monocyte-derived macrophage infiltration of islet cells is seen in type 2 diabetes and thought to play a role in causing islet pathology in that condition [32]. Such evidence supports a direct role of monocytes in the development of glucose intolerance. In this context, rather than being simply a surrogate for determining mitochondrial action or number in alternative tissues, our findings of reduced mtDNA in monocytes could imply a direct impact on the development and timing of type 2 diabetes.

By confining the age of participants to $\geq 50$ years of age, we successfully eliminated current age as a factor. However, this meant that participants with an earlier age of onset had, by definition, a longer duration of diabetes. It was therefore difficult to separate the independent effect of age of onset from that of disease duration. Conceivably, both factors may have a bearing on mtDNA content, two possibilities that are not necessarily mutually exclusive. The mtDNA molecule is particularly susceptible to damage and defective replication by virtue of continued exposure to reactive oxygen species (ROS) and a lack of DNA repair mechanisms. Furthermore, it has been shown that mtDNA harbouring deleterious mutations are preferentially clonally amplified as a compensatory response to energy deficiency by making more mitochondria and mtDNA [33]. However, with time, as defective mitochondria accumulate, bioenergetic and replicative function declines. Therefore, in addition to the possibility of lower mtDNA content predisposing to early-onset disease, it is equally possible that patients with early-onset disease, exposed to the ravages of longer diabetes duration, accumulate defects in the mitochondrial genome with resultant defective replication further depleting mtDNA content. To determine the relative extent to which the age of type 2 diabetes onset or duration of diabetes affects mtDNA, a larger study of samples taken at the time of diagnosis could be conducted. However, in such a study, the differing age of the participants (by definition) and the diabetes complications potential of the patients (which would not become evident for many years) would be confounding factors. Although we cannot separate these two factors, we favour the notion that age of diagnosis plays a greater role, as its statistical relationship with mtDNA was stronger.

Another intriguing phenomenon observed by us is that diabetes complications modify the relationship between mtDNA and the age of onset of type 2 diabetes (or duration of diabetes). Interestingly, Song et al. [13] found that patients with diabetic complications have an 'atypical increase in 
mtDNA copy number'. As monocyte populations are now recognised to be heterogeneous [34] and different monocyte populations can independently predict vascular disease [35], it is possible that monocytes in patients with diabetes complications have a different biology to those in patients without complications. Additionally, in the presence of diabetes complications, different modifiers may exist, which affect mtDNA quantity and override and mask the age of onset and/or duration of disease effects. Such influences are likely to be complex. However, several factors that are implicated in the development of diabetes complications and also affect mitochondrial biogenesis can be considered as possibilities. It is likely that patients with diabetic complications have worse glycaemic control than those without complications; moreover, the presence of diabetes complications is causally associated with overproduction of ROS primarily derived from mitochondria [36]. Interestingly, high glucose-induced overproduction of ROS has been shown to change mitochondrial morphology [37] and has a regulatory role in growth factor signalling and mtDNA replication [38]. Furthermore, different mtDNA haplotypes are associated with differences in ROS generation [38,39]. So in addition to exogenous factors impacting on ROS, e.g. high glucose, persons prone to diabetes complications could also have a mtDNA haplotype more susceptible to the production of ROS, and this may in turn impact on mtDNA replication. Similarly, reduced bioavailability of nitric oxide and defective endothelial nitric oxide synthase (eNOS) are the hallmarks of diabetic vascular complications. Coupled with the finding that eNOS can induce mitochondrial biogenesis in several tissues [40,41], it is possible that altered nitric oxide biology leads to altered mitochondrial biology in individuals who are prone to complications and that this is not seen in patients who are free of complications.

Another factor that may have impacted on the age of onset:mtDNA relationship in the complications group is the use of medications such as TZDs and statins [42,43]. However, we did not find any differences in the overall use of these medications in the complications groups, although we were not able to analyse for dose/duration effects in our cohorts.

We also found that ethnicity, $\mathrm{HbA}_{1 \mathrm{c}}$ and smoking impact on mtDNA quantity in patients with type 2 diabetes. Thus it appears that many variables other than age of onset and/or disease duration affect PBMC mtDNA content in type 2 diabetic patients. These observations may explain the conflicting findings of Song et al. [13], who reported reduced peripheral blood mtDNA content in the insulinresistant offspring (some also with diabetes) of type 2 diabetic patients in Korea, a result not seen in a cohort from the UK Warren 2 Consortium (cited by Singh et al. [44]). These clinical factors should be taken into account in future study design.
The numbers of participants in our study were relatively small, partly due to the relatively infrequent numbers with early-onset diabetes. The fact that the power calculations are within our sample range is somewhat reassuring. Nevertheless, our observations need to be confirmed in a larger cohort. Purification of the various monocyte subclasses may also help to improve the specificity of the results. It would also be interesting to explore whether the mtDNA content in readily available PBMCs is representative of mtDNA from other tissues such as islet and skeletal muscle. As this is a cross-sectional study, we also cannot rule out the possibility of a survival bias in either group. Moreover, as outlined above, a difficulty inherent in our study is the separation of age of onset from diabetes duration. We cannot therefore be dogmatic about a causal link between low mtDNA and an earlier age of onset. However, this study clearly supports the hypothesis that an earlier age of type 2 diabetes onset is associated with lower PBMC mtDNA content, intriguingly only in patients without diabetes complications.

Acknowledgements We would like to thank A. Charlton and L. Lo for their technical help in this study.

Duality of interest The authors declare that there is no duality of interest associated with this manuscript.

\section{References}

1. Yoshiharu T, Toshiharu I, Kana M, Toru E, Azuma K (2008) Predictors of glycemic control in Japanese subjects with type 2 diabetes mellitus. Metab Clin Exp 57:453-457

2. Hillier TA, Pedula KL (2003) Complications in young adults with early-onset type 2 diabetes: losing the relative protection of youth. Diabetes Care 26:2999-3005

3. Wong J, Molyneaux L, Constantino M, Twigg SM, Yue DK (2008) Timing is everything: age of onset influences long-term retinopathy risk in type 2 diabetes, independent of traditional risk factors. Diabetes Care 31:1985-1990

4. Ji L, Hou X, Han X (2001) Prevalence and clinical characteristics of mitochondrial tRNA leu(UUR) mt $3243 \mathrm{~A} \rightarrow \mathrm{G}$ and ND-1 gene $\mathrm{mt} 3316 \mathrm{G} \rightarrow \mathrm{A}$ mutations in Chinese patients with type 2 diabetes. Chin Med J (Engl) 114:1205-1207

5. Wiederkehr A, Wollheim CB (2006) Minireview: implication of mitochondria in insulin secretion and action. Endocrinology 147:2643-2649

6. Petersen KF, Dufour S, Befroy D, Garcia R, Shulman GI (2004) Impaired mitochondrial activity in the insulin-resistant offspring of patients with type 2 diabetes. N Engl J Med 350:664-671

7. Serradas P, Giroix MH, Saulnier C et al (1995) Mitochondrial deoxyribonucleic acid content is specifically decreased in adult, but not fetal, pancreatic islets of the Goto-Kakizaki rat, a genetic model of noninsulin-dependent diabetes. Endocrinology 136:5623-5631

8. Antonetti DA, Reynet C, Kahn CR (1995) Increased expression of mitochondrial-encoded genes in skeletal muscle of humans with diabetes mellitus. J Clin Invest 95:1383-1388 
9. Wang H, Hiatt WR, Barstow TJ, Brass EP (1999) Relationships between muscle mitochondrial DNA content, mitochondrial enzyme activity and oxidative capacity in man: alterations with disease. Eur J Appl Physiol Occup Physiol 80:22-27

10. Sukhorukov VS, Nartsissov RP, Petrichuk SV et al (2000) Comparative diagnostic value of the analysis of the skeletal muscle and lymphocytes in mitochondrial diseases. Arkh Patol 62:19-21

11. Lee HK, Song JH, Shin CS et al (1998) Decreased mitochondrial DNA content in peripheral blood precedes the development of non-insulindependent diabetes mellitus. Diabetes Res Clin Pract 42:161-167

12. Arkan MC, Hevener AL, Greten FR et al (2005) IKK- $\beta$ links inflammation to obesity-induced insulin resistance. Nat Med $11: 191-198$

13. Song J, Oh JY, Sung YA, Pak YK, Park KS, Lee HK (2001) Peripheral blood mitochondrial DNA content is related to insulin sensitivity in offspring of type 2 diabetic patients. Diabetes Care 24:865-869

14. ML McGill M, Yue DK, Turtle JR (1993) A single visit diabetes complication assessment service: a complement to diabetes management at the primary care level. Diabet Med 10:366-370

15. Group ETDRSR (1991) Grading diabetic retinopathy from stereoscopic color fundus photographs - an extension of the modified Airlie House classification. ETDRS report number 10. Ophthalmology 98(5 Suppl):786-806

16. Alberti KG, Zimmet PZ (1998) Definition, diagnosis and classification of diabetes mellitus and its complications. Part 1: diagnosis and classification of diabetes mellitus provisional report of a WHO consultation. Diabet Med 15:539-553

17. Gourlain K, Amellal B, Ait Arkoub Z, Dupin N, Katlama C, Calvez V (2003) Quantitative analysis of human mitochondrial DNA using a real-time PCR assay. HIV Med 4:287-292

18. Pfaffl MW (2001) A new mathematical model for relative quantification in real-time RT-PCR. Nucleic Acids Res 29:e45

19. Ochi M, Osawa H, Hirota $Y$ et al (2007) Frequency of the $G / G$ genotype of resistin single nucleotide polymorphism at 420 appears to be increased in younger-onset type 2 diabetes. Diabetes 56:2834-2838

20. Lehman DM, Hunt KJ, Leach RJ et al (2007) Haplotypes of transcription factor 7-like 2 (TCF7L2) gene and its upstream region are associated with type 2 diabetes and age of onset in Mexican Americans. Diabetes 56:389-393

21. Guo Y, Traurig M, Ma L et al (2006) CHRM3 gene variation is associated with decreased acute insulin secretion and increased risk for early-onset type 2 diabetes in Pima Indians. Diabetes 55:3625-3629

22. Jaakkola U, Pesonen U, Vainio-Jylha E, Koulu M, Pollonen M, Kallio J (2006) The Leu7Pro polymorphism of neuropeptide $Y$ is associated with younger age of onset of type 2 diabetes mellitus and increased risk for nephropathy in subjects with diabetic retinopathy. Exp Clin Endocrinol Diabetes 114:147-152

23. Flavell DM, Ireland H, Stephens JW et al (2005) Peroxisome proliferator-activated receptor $\alpha$ gene variation influences age of onset and progression of type 2 diabetes. Diabetes 54:582-586

24. Zeggini E, Parkinson J, Halford S et al (2004) Association studies of insulin receptor substrate 1 gene (irs1) variants in type 2 diabetes samples enriched for family history and early age of onset. Diabetes 53:3319-3322

25. Oliva R, Novials A, Sánchez M et al (2004) The HFE gene is associated to an earlier age of onset and to the presence of diabetic nephropathy in diabetes mellitus type 2. Endocr 24:111114

26. Wiltshire S, Frayling TM, Groves CJ et al (2004) Evidence from a large U.K. family collection that genes influencing age of onset of type 2 diabetes map to Chromosome 12p and to the MODY3/ NIDDM2 Locus on 12q24. Diabetes 53:855-860

27. Hanson RL, Bogardus C, Duggan D et al (2007) A search for variants associated with young-onset type 2 diabetes in American Indians in a $100 \mathrm{~K}$ genotyping array. Diabetes $56: 3045-3052$

28. Curran JE, Johnson MP, Dyer TD et al (2007) Genetic determinants of mitochondrial content. Hum Mol Genet 16:1504-1514

29. Silva JP, Kohler M, Graff C et al (2000) Impaired insulin secretion and $\beta$-cell loss in tissue-specific knockout mice with mitochondrial diabetes. Nat Genet 26:336-340

30. Hotamisligil GS (2006) Inflammation and metabolic disorders. Nature 444:860-867

31. Hevener AL, Olefsky JM, Reichart D et al (2007) Macrophage $\operatorname{PPAR} \gamma$ is required for normal skeletal muscle and hepatic insulin sensitivity and full antidiabetic effects of thiazolidinediones. J Clin Invest 117:1658-1669

32. Ehses JA, Perren A, Eppler E et al (2007) Increased number of islet-associated macrophages in type 2 diabetes. Diabetes 56:2356-2370

33. Wallace DC (2005) A mitochondrial paradigm of metabolic and degenerative diseases, aging, and cancer: a dawn for evolutionary medicine. Annu Rev Genet 39:359-407

34. Gordon S, Taylor PR (2005) Monocyte and macrophage heterogeneity. Nat Rev Immunol 5:953-964

35. Heine GH, Ulrich C, Seibert E et al (2007) CD14++CD16+ monocytes but not total monocyte numbers predict cardiovascular events in dialysis patients. Kidney Int 73:622-629

36. Brownlee M (2005) The pathobiology of diabetic complications: a unifying mechanism. Diabetes 54:1615-1625

37. Yu T, Robotham JL, Yoon Y (2006) Increased production of reactive oxygen species in hyperglycemic conditions requires dynamic change of mitochondrial morphology. Proc Natl Acad Sci U S A 103:2653-2658

38. Baughman JM, Mootha VK (2006) Buffering mitochondrial DNA variation. Nat Genet 38:1232-1233

39. Moreno-Loshuertos R, Acin-Perez R, Fernandez-Silva $P$ et al (2006) Differences in reactive oxygen species production explain the phenotypes associated with common mouse mitochondrial DNA variants. Nat Genet 38:1261-1268

40. Nisoli E, Carruba MO (2006) Nitric oxide and mitochondrial biogenesis. J Cell Sci 119:2855-2862

41. Tedesco L, Valerio A, Cervino C et al (2008) Cannabinoid type 1 receptor blockade promotes mitochondrial biogenesis through endothelial nitric oxide synthase expression in white adipocytes. Diabetes 57:2028-2036

42. Schick BA, Laaksonen R, Frohlich JJ et al (2007) Decreased skeletal muscle mitochondrial DNA in patients treated with highdose simvastatin. Clin Pharmacol Ther 81:650-653

43. Bogacka I, Xie H, Bray GA, Smith SR (2005) Pioglitazone induces mitochondrial biogenesis in human subcutaneous adipose tissue in vivo. Diabetes 54:1392-1399

44. Singh R, Hattersley AT, Harries LW (2007) Reduced peripheral blood mitochondrial DNA content is not a risk factor for type 2 diabetes. Diabet Med 24:784-787 